\title{
RAZPRAVE, ŠTUDIJE
}

\author{
Marko Kerševan
}

\section{LUTHROV/REFORMATORSKI»KOPERNIKANSKI OBRAT« V TEOLOGIJI IN HABITUS »MODERNEGA ČLOVEKA«}

V mnogih okoljih, tudi našem, se je vse do novejšega časa ob reformaciji največ govorilo in pisalo o zunanjih okoliščinah, na primer o neredu in zlorabah v takratni cerkvi, o političnih protislovjih takratne Evrope, o egoističnih materialnih in političnih interesih plemiških in mestnih privržencev reformacije, na primer o njihovem pohlepu po cerkvenih posestvih in cerkveni moči, vse do izpostavljanja nekih resničnih ali izmišljenih osebnih lastnosti in slabosti vodilnih reformatorjev, predvsem seveda Luthra. S tem naj bi bile pogojene in pojasnjene tudi bolj ali manj zgolj negativne posledice njihovega delovanja: delitev in cepitev krščanstva in cerkve vse do verskih vojn, razpad enotnosti krščanske Evrope, upad vernosti in začetek sekularizacije; če je bilo že kaj pozitivnega $v$ idejah in ravnanjih reformatorjev, da je bilo to znano in spoznano v cerkvi ali zunaj nje že pred njimi in bi se uveljavilo tudi brez njih.

Za 50o-letnico reformacije lahko rečemo, da jo obeležuje konec prevlade takega pristopa. Tudi v Katoliški cerkvi, ne nazadnje z II. vatikanskim koncilom in sedanjim papežem, je prišla v ospredje pozornost do pozitivnih spodbud in dosežkov reformacije (ob skupnem katoliškem in protestantskem obžalovanju negativnih posledic in priznanju krivde zanje na obeh straneh) (Dieter 2017, 183; dokument Od konflikta do skupnosti 2016, 89-91).V najnovejši in najizčrpnejši Luthrovi biografiji nemškega zgodovinarja Heinza Schillinga je tako ob vsem uvidu v globino in širino stanja in dogajanja, ki je predhodilo Luthrovemu delovanju in ga spremljalo, jasno poudarjen ključni Luthrov prispevek, ki 
ga ni mogoče odmisliti iz evropske in krščanske zgodovine ter sedanjosti (Schilling 2016, 624).

Iz obeh razlogov - dolgotrajnega ignoriranja ali vsaj omalovaževanja in sedanjega ponovnega odkrivanja temeljnih reformacijskih verskih usmeritev - je prav, da se tudi ob tej priliki na začetku na kratko vprašamo, kaj je bilo ključno in novo v verskem jedru, v »srcu«, prizadevanja Luthra in reformatorjev? Lahko bi rekli: v srcu/jedru prizadevanja reformatorjev je bila »reformacija srca«, notranja preobrazba, »sprejetje v srce « temeljnega krščanskega oznanila, kot so ga spoznali in razumeli. To in ne sprememba cerkvenih struktur, organizacije, take ali drugačne moralne, socialne ali politične pobude in zahteve navzven - čeprav prav to ni ostalo brez moralnih, kulturnih, socialnih in političnih posledic!

Ponovno odkritje in "notranje sprejetje« evangelija, evangeljskega oznanila z njegovim sporočilom o človekovem opravičenju in odrešenju, so teologi kasneje opisali z znanimi štirimi »samo«: človek je deležen opravičenja samo iz Božje milosti - samo zaradi Kristusa - samo po veri - kar vemo samo po Svetem pismu. Te štiri samo je po reformatorjih treba brati in razumeti skupaj, $v$ medsebojni povezanosti in medsebojnem omejevanju. Povezati in poudariti pa jih je mogoče na različne načine in že odtod tudi različne posledice njihovega sporočila. ${ }^{1}$

Kot sociolog bom izpostavil nekatere zveze in poudarke, ki so imeli posebej pomembne posledice za človekovo držo in delovanje v »svetu«. Omejil bi se na tri, ki so pri različnih avtorjih (na primer Kraus 1982) že dobili oznako »kopernikanskega obrata « v verskem pojmovanju, v teologiji in preko tega $\mathrm{v}$ drži in ravnanju vernika nasproti svetu. V čem naj bi bil ta kopernikanski obrat (čeprav menda Luther ni hotel nič slišati o Kopernikovem heliocentričnem obratu: Biblija mu tega ni dovoljevala)?

1 Iz obsežne literature o tem bi rad opozoril na novejšo razpravo Ulricha Körtnerja, pripravljeno za skupni kongres Evangeličanske cerkve v Nemčiji (EKD) in Švicarske evangeličanske cerkvene zveze (SEK) ob 50o-letnici reformacije (Körtner 2014, slovenski prevod v Stati inu obstati št. 26 (2017)), ter na izčrpno razpravo o pomenu reformatorskih izključujočih samo v Jünglovem odmevnem delu Evangelij o opravičenju brezbožnega kot središče krščanske vere, posebej o sola fide (Jüngel 1999, 126-220; slov. prevod poglavja »Le po veri« v Jüngel 2001, 159-79). Splošneje v Kerševan 2012, 21-24, 57-71. 


\section{Nekateri poudarki Luthrove/reformatorske teologije}

Najprej poudarek na človeku kot posamezniku in njegovi svobodi. V odnosu med Bogom in človekom štejeta navsezadnje samo človek kot posameznik in njegova notranja vera. Odrešenja človeku ne more posredovati in še manj zagotoviti pripadnost neki skupnosti ali ustanovi, tudi vnaprejšnja in zunanja pripadnost pravi cerkvi ne. V zadevah »srca«kot mesta in načina človekovega srečanja $\mathrm{z}$ Bogom, $\mathrm{v}$ zadevah vere in vesti, je človek svoboden nasproti vsem skupnostim in ustanovam, tudi nasproti cerkveni instituciji. $^{2}$

Tudi renesansa in humanizem tistega časa sta poudarila posameznika in njegovo svobodo - toda pri tem sta imela pred očmi predvsem velike, izjemne posameznike. Reformacija in reformatorji pa so imeli pred očmi vsakega človeka, saj je Bog preko Kristusa poklical vsakega človeka, ne zaradi njegovih del in zaslug, ne zaradi zunanjih pripadnosti in dosežkov, ampak le iz svoje milosti zaradi Kristusa: ni ne Juda ne Grka, ne moškega ne ženske, ne gospodarja in ne sužnja, vsi so eno v Kristusu

2 Med že klasičnimi avtorji je v tej zvezi prav ponovno opozoriti na Troeltschevo delo Pomen protestantizma za nastanek modernega sveta (Troeltsch 1911, 14345) in na Simmla, ki/ko lapidarno povzema: "Krščanski Bog (reformatorjev) je Bog posameznika [...] posameznik stoji pred Bogom v popolni samoodgovornosti." (Simmel 1912/1989, 161) Med sodobnimi sociologi zasluži posebno pozornost razprava Hansa-Georga Soeffnerja »Luther -Pot od kolektivitete vere k luteransko-protestantskemu tipu individualitete (Soeffner 1992, 20-75); na kratko jo povzema tudi Ulrich Beck (2009, 131-38). Teološko je posebej pronicljiva in temeljita analiza Eberharda Jüngla O kristjanovi svobodi: spomin na Luthrov spis (Jüngel 1991, 54-115). Jüngel se v njej sooči tudi z znano Marcusejevo - in že prej Schellerjevo - tezo, da je (luteransko) povzdignjenje posameznikove "notranjosti« in njegove "notranje svobode" služilo (Nemcem) kot alibi za nedejavnost ali za opravljanje kakršne koli dejavnosti, saj ta ne zadeva edino ključne »notranje« svobode in odgovornosti. Po Jünglu »obrat [die Wende] vere« ni premik od ene »antropološke danosti« k drugi, od telesnosti, zunanjosti, posvetnosti k duši, notranjosti, onstranski usmerjenosti, ampak s Kristusom omogočeni obrat/sprememba "starega človeka" v "novega «, svobodnega in za delovanje v svetu odgovornega človeka: $\mathrm{z}$ vero in po veri človek ni več »zakrivljen vase« (Luther), ampak lahko »izstopi iz sebe« in se obrne k drugemu, svetu in Bogu. 
Jezusu, piše apostol Pavel (Gal 3,28). Vsak človek je nagovorjen in odgovoren kot posameznik, v svojem srcu.

Zlasti sociologi kot Max Weber so že zgodaj ugotavljali, da je reformacija na poseben verski način usmerila ljudi $k$ svetu in dejavnosti v njem (Weber 1988; Weber 2015: 49-74 in drugod). Do tedaj prevladujoča - ljudska in cerkvena - religioznost je bila obsedena $\mathrm{z}$ vprašanjem, $\mathrm{s}$ katerimi svetimi dejanji, na katerih svetih krajih in ob katerih svetih časih, s pomočjo katerih svetih posrednikov - od Marije in svetnikov do cerkvenih svečenikov - se je mogoče čim bolj približati Bogu, doseči njegovo pozornost in njegovo naklonjenost, si zagotoviti odrešenje na onem in pomoč na tem svetu. Odmevi tega so še živi v nekaterih cerkvah, tudi katoliški, in okoljih, kjer prevladujejo. Po reformatorjih je bila in je taka usmerjenost odveč, zgrešena, navsezadnje grešna. Po Kristusu in zaradi Božje milosti človeku ni treba več biti v skrbeh in skrbeti za svoje odrešenje. Po veri in $\mathrm{z}$ vero je zaradi Kristusa in Božje milosti človek lahko gotov svojega odrešenja (kot je za apostolom Pavlom poudarjal Calvin). ${ }^{3}$ Za odrešenje in gotovost odrešenja zadošča človekova vera, ne pa kakšna magična ali duhovna "tehnologija« ali praksa, ki bi pomagala k onstranski učinkovitosti človekovega prizadevanja. ${ }^{4}$

Človek, ki/ko je osvobojen/razbremenjen skrbi in prizadevanja za onstranstvo ter onstransko pomoč, je hkrati osvobojen za tostranstvo,

3 O Calvinu in njegovem nauku o odrešenju, posebej o predestinaciji, glej do zdaj edini prevod iz njegove Institutio religionis christianae v slovenščino v reviji Stati inu obstati (Calvin 2009, 341-75).

4 Zgodovinar Jean Delumeau v svojem raziskovanju »zgodovine mentalitet« (v knjigah Strah na Zahodu in Greh in strah: ustvarjanje občutja krivde na Zahodu od 13. do 18. stoletja) obsežno dokumentira občutenje strahu (in ustvarjanje tega občutja) v takratni, pretežno katoliški Evropi. Ugotavlja, da je reformatorski, Luthrov in Calvinov nauk o opravičenju z razglašanjem vere/zaupanja v milostnega Boga ponujal izhod iz obsedenosti s strahom, toda v sklepnem poglavju svoje raziskave pokaže tudi, kako se je v protestantskem verskem okolju strah še dolgo ohranjal ali dobival nove vzpodbude s predstavo bližnjega »konca časov«, $\mathrm{z}$ ambivalentnostjo nauka o (dvojni) predestinaciji, $\mathrm{z}$ naravnimi, družbenimi in moralnimi stiskami ter katastrofami, ki so govorile, da je satan še vedno moč ali celo vladar "tega sveta«, pa tudi z »vzgojnimi prijemi« protestantskih pastorjev, ki da se pri tem pogosto niso razlikovali od katoliških kolegov (Delumeau 1986, 733-836). 
za posvetno prizadevanje in dejavnost. Charles Taylor, vplivni katoliški raziskovalec moderne družbe in krščanske vernosti v njej, je to takole izrazil:

Polnost krščanske eksistence je zdaj v normalnem življenju, v poklicu, v zakonu in družini [...] ves moderni razvoj pritrditve normalnemu življenju v vseh njegovih odtenkih je po mojem prepričanju vsebovan $\mathrm{v}$ duhovnosti reformatorjev; to velja tako za pozitivno vrednotenje produkcije in reprodukcije kot za nasprotovanje hierarhiji, zakramentalni avtoriteti in višjim poklicem. (Taylor 2002, 253)

Učinkovitost, storilnost ni več vprašanje religioznega delovanja, ${ }^{5} \mathrm{am}$ pak zgolj posvetne, v svet usmerjene dejavnosti. Še več, lahko bi rekli, da je bil verni človek, ki je bil osvobojen religiozne skrbi za onstranstvo, zdaj zato na religiozen način zavezan k skrbni, učinkoviti tostranski, posvetni dejavnosti, v prvi vrsti svoji delovni in poklicni dejavnosti. Ob vseh drugih razlogih za prizadevno in uspešno delo je zdaj namreč postala tudi prostor in čas za izražanje hvaležnosti Bogu za zastonjsko pridobljeno milost odrešenja: ${ }^{6} \mathrm{z}$ dobrim delom $\mathrm{v}$ končnem svetu človek hvaležno odgovarja na neskončno Božjo dobroto v zadevah neskončnosti. Z dobrim delom v obeh pomenih: dobrim, ker je dobro opravljeno, v skladu s človekovimi notranjimi zmožnostmi in zunanjimi možnostmi ter dobrim v tem smislu, da je dobro za ljudi in njihovo dobro. Pri reformatorjih lahko beremo, kako je najvišja božja služba po eni strani

5 Schilling govori o »obratu od srednjeveške storilnostne religioznosti [Leistungsfrömmigkeit] k evangeljski religiji milosti [Gnadenfrömmigkeit] na temelju načela sola gratia, ki je odprl pot novodobni poklicni etiki in usmeril kristjana na njemu primerno delovanje $\mathrm{v}$ svetu [...] Vera brez učinkovanja $\mathrm{v}$ svetu je bila prav tako grešna in oddaljena od Boga kot delovanje $\mathrm{v}$ svetu brez vere. Na tej osnovi je postala in ostala religija skozi več stoletij dejavna sila novega veka - kulturno, družbeno in politično." (Schilling 2016, 642-43)

6 Posebej jasen je o tej zvezi Heidelberški katekizem, najvplivnejši katekizem reformirane/kalvinske usmeritve. Sestoji iz treh delov: O človeški bedi, O odrešenju človeka, O hvaležnosti. Ljudje naj bi delali dobra dela (vpr. 32), da bi bili Bogu hvaležni za njegova dobra dela (odrešenja). 
vera sama, po drugi strani pa je prava božja služba človekovo posvetno delo, če je opravljano Bogu v (za)hvalo in ljudem v dobro.

Tako naj bi "novo « oziroma pravo verovanje delovalo pri trdno verujočih; drugim so svetovali, naj delajo tako, kot delajo tisti, ki trdno verujejo: če bodo to zmogli, bodo s tem preverjali/potrjevali zaresnost svoje vere ali jo v sebi šele odkrili. Navsezadnje se vprašanju/dvomu o zaresnosti svoje vere ni mogel izogniti nihče, če je le veljalo Luthrovo opozorilo v 30. tezi njegovih slavnih petindevetdesetih tez o odpustkih iz leta 1517: "Nihče ne more biti prepričan o pristnosti/zaresnosti [Wahrhaftigkeit] svojega kesanja." (Luther 2001, 111.) Zaresnost kesanja je neizogibna sestavina zaresne vere. Nekateri, morda celo najštevilnejši, so si pomagali s sklepanjem, da uspeh pri delu že sam govori o Božji naklonjenosti in izbranosti za odrešenje (Weber 1988).

In še tretji, najgloblji, najbolj temeljno krščanski vidik Luthrovega/ reformatorskega »kopernikanskega obrata« v sami religiji, v razumevanju človekovega odnosa do Boga in sveta. Luther je leta 1517 zapisal: človek - grešni človek, to je vsak človek - noče, da bi bil bog Bog, rad bi bil sam bog (WA 1, 225; po Jüngel 1991, 23). Še posebej noče, da bi bil Bog bog, kakršen se je razodel v Jezusu Kristusu (dodaja in pojasnjuje Luthrovo spoznanje Karl Barth). ${ }^{7}$ Hoče in išče vzvišenega boga; boga, ki je samozadosten in vsemogočen, poln moči. Človek si prizadeva, da bi bil (vsaj malo) sam tak bog, da bi si prisvojil vsaj delček te božje moči - vsaj tako, da bi bil deležen take moči preko božje pomoči. S svojimi mislimi se hoče povzpeti čim bližje božji višini, se s poglobitvijo vase približati božji globini, z magično religioznimi obredi in molitvami priklicati božjo (po)moč. Pri tem vedno znova pozablja, da je naš bog Bog, ki se je učlovečil, ki je postal človek, da bi bil s človekom kot človek in Bog; da je to storil po svoji volji in svobodi. ${ }^{8}$ (In da s člo-

7 Pisanje Bog/bog z malo ali/in veliko začetnico v slovenščini pomeni neko neizogibno (in hkrati ne nesporno) interpretacijo, ki se ji (nemško) pisanje vsakega samostalnika vedno $\mathrm{z}$ veliko začetnico izogne (oziroma jo preloži na bralca ali na dodatna pojasnjevanja).

8 Jezus Kristus, Učlovečeni Božji sin, za človeka ni le edina pot do pravega spoznanja (podobe) Boga, ampak tudi pot do spoznanja človeka samega, njegove - s človeške strani nepremostljive - razlike od Boga, razlike, ki jo je šele Bog pokazal in 
vekom ostaja, tudi če človek v to dvomi, če ga zavrača ali išče drugega in drugačnega boga.) ${ }^{9}$

Predmet krščanskega verovanja je, da se je Bog učlovečil, da je Bog s človekom, da ni Boga brez človeka - tudi če si človek domišlja ali želi, da je ali da bi bil brez Boga. Božje učlovečenje pomeni, da je Bog v Kristusu sprejel nase tudi človeško šibkost, stiske, smrt; pomeni, da je s človekom tudi v njegovih stiskah in smrti, ne pa da jih kot vzvišena božja moč v tem svetu odpravlja. Bog, ki se je kot človek rodil v hlevu in umrl sramotne smrti na križu, je s človekom tudi v bedi in smrti, čeprav je kot Bog, ki je s Kristusom zmagoslavno vstopil v tempelj, s človekom tudi v njegovih uspehih in zmagah. Toda: beda, stiske, smrt, kot tudi uspehi in zmage, ostajajo človeške zadeve, stvar človeške (ne)moči, človeških (z)možnosti in ne(z)možnosti. In prav tako je s človeškimi ustanovami in skupnostmi. So človeške, ne božje zadeve, rezultat in sredstvo človeških nagibov, človeških moči, zmožnosti in nezmožnosti prave presoje in pravega delovanja pri prizadevanju za več boljšega življenja, $z$ vsemi medsebojnimi nesoglasji in spopadi pri tem. Z njimi stoji pred Bogom in njegovo obljubo odrešenja in Božjega kraljestva - Bogom, ki človeka sprejema, in obljubo, ki ga spodbuja in usmerja, da ne pristane na obstoječe bede in stiske, tudi če jih sam ne bo zmogel dokončno in docela

premostil z učlovečenjem v Jezusu Kristusu, ko je sprejel človeka takega, kot je, kot grešnika in ne kot malega boga/pravičneža, kar hoče biti. Luther: »Kot smo se $\mathrm{v}$ Adamu povzpeli $\mathrm{k}$ Božji podobi, tako se je on [v Kristusu] spustil v našo podobo, da bi nas privedel do spoznanja samih sebe.» (WA 19, 207, 3-6)»Iz nesrečnih in oholih bogov je naredil spet resnične ljudi, to je trpeče in grešne." (WA 5, 128, 36-39) V pismu Spalatinu Luther opozarja na »vsem nam v raju od hudiča vsajeno stremljenje, da bi bili sami Bog» in poudarja »bodimo ljudje in ne bog(ovi): to je summa« (WA B 5, 415, 41-46). O tem obsežneje Jüngel (1991, 16-27; od tam tudi zgornji Luthrovi citati); v slovenščini o tem obsežneje pišem v knjigi Vstop v krščanstvo drugače (Kerševan 1992, 69-73, 86-92), kjer prikazujem na Luthra opirajočo se misel Karla Bartha in njeno nadaljnje razvijanje po Eberhardu Jünglu.

9 „Če po besedah sprave ni Boga brez človeka (KD IV/3, 133). potem človek ne more postati absolutno brezbožen, ne more biti absolutno brez Boga.« (Jüngel 1982, 345) »S svojo brezbožnostjo človek ne more narediti Boga za brezčloveškega.« (Barth) Po Jünglu ni nobenega (Božjega) »zgoraj«, v katerem ni človeka, in tudi ne nobenega človeškega »spodaj«, kjer ni Boga. Prim. Kerševan 1992, 90-91. 
odpraviti. Sociolog Niklas Luhmann je ta premik/obrat vključil v svoje pojmovanje sekularizacije in ga v svojem jeziku lapidarno opredelil: »S sekulariziranjem je bila registrirana nevidnost Božje roke« (natančneje: »s sekulariziranjem je bilo registrirano, da Božje roke ni mogoče narediti vidne in da le monde va de lui-meme.«(Luhmann 2002, 285.)

\section{"Moderni človek" in značilnosti "moderne družbe» v sociologiji}

Naj bo zgornja pritegnitev in pridružitev misli sodobnega sociologa, predstavnika radikalne sistemske teorije, k teološkim opredeljevanjem in interpretacijam ilustracija temeljne teze tega predavanja/članka o ujemanju reformatorskih (teoloških) pojmovanj in spoznanj o (krščanski) veri s pojmovanji in spoznanji sociologije o modernem človeku in/v moderni družbi. Nič manj in nič več. Ostali bomo pri ohlapnem govoru o »ujemanju«, ne da bi skušali natančneje opredeljevati ravni in načine tega ujemanja, povzemati ali razvijati, potrjevati ali zavračati kakšne natančnejše hipoteze o medsebojni vzročni, funkcijski, strukturni ali kakšni drugi povezanosti in njeni smeri. ${ }^{10}$

Ko govorimo o sodobnem/modernem človeku, imamo lahko pred očmi »empiričnega« človeka, se pravi rezultat nekih posplošenih (samo) opazovanj, raziskovanj, pričevanj, nenazadnje v literaturi in umetnosti, lahko pa nek »idealnotipski« ali celo normativni zbir lastnosti in usmeri-

10 Iz klasične sociologije bi tudi tokrat lahko vzeli za ilustracijo Marxovo opredelitev v Kapitalu 1863 (ki zgolj ohlapno govori o funkcijski povezanosti): »Za družbo producentov blaga [...] je krščanstvo, s svojim kultom abstraktnega človeka, zlasti v meščanskem obdobju svojega razvoja, v protestantizmu, deizmu itd. najprimernejša oblika religije." (Marx 1980, 209) Razvita in univerzalizirana »družba producentov blaga « je za Marxa seveda moderna kapitalistična družba. V Teorijah o presežni vrednosti (1863) pravi: „Kapitalistični način produkcije je enako kozmopolitski kot krščanstvo. Zato je krščanstvo specialna religija kapitala. Pri obeh velja samo človek. Sam po sebi je en človek prav toliko vreden kot vsak drug. Pri prvem je vse odvisno od tega, če ima vero, pri drugem pa, če ima kredit« $(1863,207)$. O tem pišem v razpravi »Religija in družbena formacija« (Kerševan 1980, 117-212). 
tev, ki jih pripisujemo ljudem sodobnega/modernega časa ali/in moderne družbe. Očitno pa je tudi opredelitev/razmejitev modernega časa ali časov vse prej kot samoumevna: gre za čas »novega veka«, čas zadnjih dveh stoletij (po francoski revoluciji, na primer), čas od začetka 2o. stoletja ali šele od konca 2. svetovne vojne? Razmejitve so seveda povezane $\mathrm{z}$ različnimi pojmi/pojmovanji »moderne družbe«, bodisi bolj empiričnih bodisi normativnih (»ideoloških«). Odprto ostaja seveda tudi vprašanje o kokoši in jajcu: so "moderni ljudje« ustvarili/spremenili moderno družbo ali je moderna družba ustvarila/prilagodila modernega človeka - in pri tem uspela le delno, žal ali k sreči ... Sociološka pojmovna orodja »idealnega tipa» (Weber), »habitusa» (Bourdieu), pa govor o formi mentis, dominantnem tipu osebnosti (Riesman) ipd., skušajo preseči slepe ulice, v katere vodijo radikalne, "ali-ali« zastavitve omenjenih dilem. Naj posebej spomnim samo na danes že nekoliko (neupravičeno) pozabljeno analizo Davida Riesmana in razlikovanje med tipi osebnosti, imenovanimi tradion directed, inner directed in others directed. Za moderno družbo naj bi bila značilna zadnja dva tipa; natančneje: v (takratni ameriški) sodobnosti naj bi začel dominirati zadnji, na račun »notranje « usmerjenega, h kateremu naj bi ravno pripomogla tudi reformacija, ko je pomagala spodkopati tip osebnosti, ki jo usmerja predvsem tradicija (Riesman 1950). ${ }^{11}$

Že klasične, klasično različne, sociološke obravnave (zahodne) "modernosti«, moderne družbe in modernega posameznika (Marx, Durkheim, Weber, Troeltsch, Töennies, Simmel, Parsons) vendarle kažejo visoko stopnjo soglasja o nekaterih značilnostih "posameznika modernih družb « ali »družb modernih posameznikov«, ne glede na različno zastavljena vprašanja in rešitve gornjih dilem. Tudi novejše klasično različne zastavitve in teorije (ilustrirajmo jih $\mathrm{z}$ Luhmannom in Luckmannom) se jim v tem pridružujejo. ${ }^{12}$ Reprezentativen, ali če ho-

11 Nadaljnji »razvoj« ali karikatura »po drugih usmerjanega« in hkrati egocentričnega posameznika naj bi bil (post) »moderni narcis « Christopherja Lascha (Lasch 1979, glej tudi Lasch 1995: tretje poglavje ima naslov »Temna noč duše«, kjer posebej spregovori o »človekovi duši pod sekularizmom«).

12 V zvezi z vprašanjem sodobne religioznosti teze in ugotovitve novejše sociologije (religije) o »modernem posamezniku« in posebej o sodobnem (tudi institucionaliziranem) individualizmu povzema Ulrich Beck v svojem (tudi v slovenšči- 
čemo: "plakativen «, za te razprave in raziskave je naslov knjige Norberta Eliasa (najbolj znanega po delu O procesu civiliziranja) - Družba individuov (Elias 1987). Njegov prvi spis s tem naslovom je izšel že leta 1939. Na svojevrsten paradoks/obrat (ki pa ne zanika, ampak potrjuje dosedanji razvoj) opozarja Peter Sloterdijk. Moderni (»ameriški/amerikanizirani«) posameznik, ki ga je reformatorska vera (in razsvetljenstvo) navedla in navadila na self-reliance pri prizadevanju za tostransko, posvetno uspešnost/storilnost, je začel vero samo doživljati in eksperimentalno preizkušati/izbirati kot sredstvo pri doseganju te uspešnosti; v veri išče "notranjo energijo in samozavest pri vztrajanju in prizadevanju - tista, ki je v tem učinkovita, je tudi resnična (Sloterdijk 1997, 27-29). Vera je navsezadnje vera v vero $\mathrm{v}$ uspeh. Sloterdijk o tem piše v predgovoru $\mathrm{k}$ nemški izdaji znanega dela Williama Jamesa o raznolikosti religioznega izkustva, ki opisuje tudi tak pragmatizem ameriške "posvetovljene« religioznosti (32).

Skozi različne teorije (in mimo njih) lahko rečemo, da živimo danes $\mathrm{v}$ svetu in družbi (institucionaliziranega in/ali doživljenega) individualizma, v kateri se poudarja posameznika, njegove pravice in njegovo svobodo; v svetu, ki je ves usmerjen $\mathrm{v}$ (kapitalistično, tržno, tekmovalno) storilnost $\mathrm{v}$ produkciji in potrošnji; v svetu in družbi, v kateri se vse človeške zadeve in ustanove obravnavajo ter urejajo sekularno, »kot da boga ne bi bilo«. Individualizem, storilnost, sekularnost so med ključnimi stvarnostmi in vrednotami sodobne družbe. Ne glede na klasične in novejše raziskave in razprave o teži in primarnosti/sekundarnosti verskih, kulturnih, političnih, ekonomskih dejavnikov in kontekstov lahko rečemo, da niso nastale brez reformatorskih spoznanj in spodbud,

no prevedenem) delu Lastni Bog (2009, 103-38, 148-80). V slovenščini je dostopno Luckmanovo delo Nevidna religija z njegovo razpravo o "avtonomnem posamezniku« modernih družb (in mitu o njem) (Luckmann 1997); Niklas Luhmann, vrhunski mojster sistemske teorije, se ob sistemski analizi modernih družb posebej ustavi ob vprašanju »izdiferenciranja « sfere (posameznikove) intimnosti v teh družbah (Luhmann 1991). Sam sem o (samo)razumevanju posameznika, o »humanistični ideologiji« in/kot "problemu religije v sodobni družbi« pisal v knjigi Religija kot dužbeni pojav (1975, 176-208) in še prej (glej Kerševan 1980, 214-26; tudi Kerševan 2011, 67-108). 
čeprav, kot poudarjata že Troeltsch in Weber, niso enostavno zrasle iz njih ali celo samo iz njih. Imele so še druge vire in spodbude. Uveljavile so se, ko in ker je prišlo do njihovega medsebojnega vplivanja, zlivanja in prepletanja, pa čeprav s tem tudi njihovega različnega razumevanja in notranjih nasprotij pri njihovem uresničevanju. Toda uveljavile so se, a žal tudi na načine, ki jih danes občutimo kot del tistega, čemur pravimo stiska, kriza ali celo brezpotje moderne družbe: individualizem, ki se udejanja kot odkriti ali zakriti brezobzirni egoizem, globalizirana storilnost $\mathrm{v}$ proizvodnji in potrošnji, ki ogroža okolje in ljudi kot psiho-fizična bitja, sekularnost, ki se jo razume kot razpoložljivost vsega za dobiček in užitek privilegiranih egoističnih posameznikov sedanjih generacij.

\section{Kritični potencial reformatorskega krščanstva $v$ razmerah krize (vrednot) kapitalistične modernosti}

Očitno je tudi, da danes vse troje deluje brez neposredne navezave ali opore na reformatorsko krščanske korenine in spodbude (kar je za storilnostno poklicno usmerjenost $\mathrm{v}$ svojem času ugotavljal že Weber, za potrošništvo pa $\left.\mathrm{Marx}^{13}\right)$. Toda ob krizi in upravičeni kritiki na račun individualizma, proizvodno/potrošniške usmerjenosti, sekularnosti modernega življenja se moramo zavedati tudi teh njihovih korenin; zavedati se moramo, da so legitimna dediščina reformatorskega krščanstva. Zavreči jih, bi pomenilo zavreči tudi dediščino reformacije, pa re-

13 Vredno se je spomniti na to zgodnjo Marxovo napoved v Očrtih kritike politične ekonomije 1857: "Na drugi strani zahteva [kapitalistična] produkcija relativne presežne vrednosti produkcijo nove potrošnje [...] prvič, kvantitativno povečanje obstoječe potrošnje, drugič, ustvarjanje novih potreb s propagiranjem obstoječih v širšem obsegu, tretjič, produkcijo novih potreb, odkrivanje in ustvarjanje novih potrošnih dobrin, [...] zato raziskovanje celotne narave, da bi odkrili nove koristne lastnosti stvari, univerzalna izmenjava produktov vseh dežel [...]. Odtod razvoj naravoslovja do najvišje točke; ravno tako odkrivanje, ustvarjanje in zadovoljevanje novih potreb, ki izhajajo iz družbe, tudi kultiviranje vseh lastnosti družbenega človeka ..... Več o tem v Kerševan 1980, 159-82, citat 181. 
nesanse, humanizma, razsvetljenstva - nenazadnje specifičnosti zahodnega krščanstva, saj je vse našteto zraslo iz njega ali v soočanju z njim.

Pogled v zgodovino - tudi ne tako oddaljeno - nam kaže, da moramo biti previdni pri predlogih/alternativah, ki povzdigujejo skupnost na račun posameznika, njegovih pravic in njegove svobode; ${ }^{14}$ ki obračajo oči $k$ nebu na račun skrbi za zemeljske zadeve; ki se pri delovanju ustanov ali lastnem delovanju sklicujejo na Boga, Božjo moč in Božje ukaze namesto na omejene človeške moči ter lastno odgovornost za presoje in delovanje. To niso ne realistične ne želene alternative. Nenazadnje bi vodile (in so vodile) k neki drugačni religiji, nasprotni reformatorskemu krščanstvu in bistvu krščanstva sploh.

Očitno nismo oziroma nisem več pri sociološko distanciranem predstavljanju nekih procesov in alternativ: gre za dileme, želje in bojazni, ki jih danes doživljamo, ne glede na to, kako jih razumemo in razlagamo (ali jih niti ne zmoremo racionalno pojasniti)!

In če se modernemu individualizmu, človekovi svobodi, tostranski usmeritvi, sekularnosti ne moremo in ne želimo odreči tudi zaradi njihovih krščanskih korenin in spodbud, ali nas to ne usmerja k vprašanju: ali je v samem jedru reformatorskega krščanstva osnova in spodbuda ne za opustitev - za reformiranje tudi obstoječega individualizma, obstoječe posvetne in sekularne drže, da se znebijo sprevrženih oblik ali da se jih vsaj zavre v njihovem razraščanju?

Reformatorsko dojeto krščanstvo se ne more in ne sme odreči temeljnosti človeka kot posameznika v odnosu do Boga: človek je odgovoren, opravičen, deležen Božje milosti kot posameznik. Toda odgovoren in odrešen je pred Bogom in po Bogu, ki je »Oče naš«, ki je »Emanuel« (»Bog z nami«) - ne z nami kot neko posebej izbrano zemeljsko skupnostjo ali ustanovo, narodom, raso, posebno cerkvijo, ampak z nami kot skupnostjo ljudi, ki so zbrani v njegovem imenu oziroma vseh, ki jim je Bog Oče in Jezus Odrešenik, vseh ljudi torej. Če je verujoči človek po takem bogu osvobojen skrbi in prizadevanja za lastno zve-

14 Mimogrede: Marxov in Engelsov Komunistični manifest iz leta 1848 ne sodi med take predloge/alternative, saj naj bi bila po njem prava bodoča družba »asociacija, $\mathrm{v}$ kateri je svoboden razvoj slehernega posameznika pogoj za svoboden razvoj vseh«. 
ličanje in je zato prost, svoboden za delo in delovanje v svetu - je prav zaradi te osvoboditve in hvaležnosti zanjo usmerjen in zavezan, da dela dobro, za dobro ljudi skupnega Očeta in Odrešenika; le tako lahko živi in dela Bogu v hvalo ter zahvalo za svoje življenje in odrešenje. Bog, Božji Sin se je učlovečil v človeku Jezusu: Jezusova človeškost je bistveno sočloveškost. »Jezusova humaniteta je v njegovi biti za človeka« in »iz zaveujočosti tega vzgleda« izhaja, da je »humaniteta vsakega človeka v določenosti njegove biti [Sein] kot sobiti [Zusammensein] z drugim človekom«. Tudi človeškosti slehernega človeka, njegove svobode, »samouresničevanja«, odnosa do Boga (zato) ni brez in zunaj sočloveškosti, brez sočloveka. Človeškost, ki izhaja iz »jaz sem «brez sočloveka, je nečlovečnost, protičloveškost (Barth 1967, 10-16, 35). Če je, kot zapiše apostol Pavel, "vse dovoljeno«, je treba upoštevati tudi, da »ni vse k pridu«, »da ni vse koristno«, da naj pri tem »nihče ne išče svoje koristi, temveč (korist) drugega«, kot zapiše v nadaljevanju (1 Kor 10,23-24). In če je človek po reformatorskem spoznanju napoten, da deluje v svetu in družbi samostojno, »brez boga«, to je ne da bi iskal in si skušal pridobiti Božjo moč ter pomoč - ne da bi računal nanjo, je za svojo samostojnost in svobodno uporabo svoje moči hkrati odgovoren: Bogu, "pred katerim stoji in od katerega je to svojo samostojnost ter svoje človeške moči prejel, in ljudem, preko katerih jih je postal deležen.

K takemu individualizmu, posvetnosti, sekularnosti nas usmerjajo reformatorji, ki se jih letos spominjamo - če se jih spominjamo pozorno in s ponovnim premislekom. Verjetno to ni dovolj, da bi s tem preglasili danes - tudi v nas samih - prevladujoči tip individualizma, samozadostnosti, samoodgovornosti oziroma neodgovornosti. Toda kot spoznanja in ravnanja reformatorjev niso sama reformirala takratnega verovanja, cerkve, družbe, ampak le, ker, kjer, ko in kakor so se ujela $\mathrm{v}$ umu in srcu ljudi in v družbi - $\mathrm{z}$ drugimi spoznanji in s prizadevanji drugih, nam tudi danes ostaja upanje, da se bodo spet in prav ujela $\mathrm{z}$ drugimi idejami in spodbudami $\mathrm{v}$ novo ali nadaljevano reformacijo. Revolucije in kontrarevolucije $\mathrm{z}$ vsem, kar jih nosi in kar prinašajo, so nam še preblizu, da bi si jih spet želeli ... 
Na začetku svoje poti, poti reformacije, je Luther zapisal: »Taka reformacija [...] je zadeva vsega sveta, pravilneje Boga samega. Čas zanjo pa je poznan le Njemu, ki je čas ustvaril.«(WA 1, 627, 27-31) ${ }^{15}$

\section{LITERATURA}

Barth, Karl. 1967. Mensch und Mitmensch: Die Grundform der Menschlichkeit. (Iz Die kirchliche Dogmatik, Bd. III, 2). Gottingen: Vandenhoeck \& Ruprecht.

Beck, Ulrich. 2009. Lastni Bog. Ljubljana: Claritas.

Campi, Emidio. 2015. »Ali je bila reformacija nemški dogodek?« Stati inu obstati: revija za vprašanja protestantizma 11 (21-22): 41-64.

Calvin, Jean. 2009. »Institutio Religionis christianae/Temelji krščanske vere.« Izbor ur. Marko Kerševan. Stati inu obstati: revija za vprašanja protestantizma 5 (9-10): 353-75.

Delumeau, Jean. 1986. Greh i strah: stvaranje osećanja krivice na Zapadu od XIV do XVIII veka. Novi Sad: Književna zajednica.

Dieter, Theodore. 2017. »Od konflikta do skupnosti.« Stati inu obstati: revija za vprašanja protestantizma 13 (25): 176-85.

Elias, Norbert. 1987. Die Gesellschaft der Individuen. Frankfurt am Main: Suhrkamp.

»Heidelberški katekizem 1563.« 2001. Poligrafi 6 (Tematska številka o protestantiz$\mathrm{mu})(21-22)$ : 71-106.

Jüngel, Eberhard. 1991. Zur Freiheit eines Christenmenschen: eine Erinnerung an Luthers Schrift. München: Kaiser Verlag.

---. 1999. Das Evangelium von der Rechtfertigung des Gottlosen als Zentrum des christlichen Glaubens. Tübingen: Mohr Siebeck.

---. 2001. »Le po veri (sola fide).« Poligrafi 6 (Tematska številka o protestantizmu) (21-22): 159-80.

Kerševan, Marko.1975. Religija kot družbeni pojav. Ljubljana: Mladinska knjiga.

---. 1980. Razredna analiza in marksistična družbena teorija. Ljubljana: Delavska enotnost.

---.1992. Vstop v krščanstvo drugače: protestantska teologija Karla Bartha v našem času in prostoru. Ljubljana: Cankarjeva založba.

---. 2011. Izbrani spisi: sociologija-marksizem-sociologija religije. Ljubljana: Filozofska fakulteta.

---. 2012. Protestanti(sti)ka. Ljubljana: Cankarjeva založba.

---. 2015. "Protestantizem v času krize in kritike moderne družbe. « Stati inu obstati: revija za vprašanja protestantizma 11 (21-22): 252-72.

Körtner, Ulrich. 2014. »Exklusiver Glaube - Das vierfache 'Allein' reformatorischer Theologie." V 50o-Jahre Reformation: Bedeutung und Herausforderungen, ur. Petra

15 Navajam po Campi 2015, 63; avtor seveda citira Luthra v drugem kontekstu. 
Bosse-Huber, 68-87. Zürich: Theologischer Verlag Zürich. (Slov. prevod v Stati inu obstati: revija za vprašanja protestantizma 13 (26)).

Kraus, Hans Joachim. 1982. Theologische Religionskritik. Neukirchen: Neukirchener Verlag.

Lash, Christopher. 1979. The Culture of Narcissism. New York: Norton.

---. 1995. The Revolte of the Elites and the Betrayal of Democracy. New York: Norton. Luckmann, Thomas. 1997. Nevidna religija. Ljubljana: Krt.

Luhmann, Niklas. 1991. »Ljubezen kot strast: h kodificiranju intimnosti.« Časopis za kritiko znanosti 19 (140-141): 47-70.

---. 2002. Die Religion der Gesellschaft. Frankfurt am Main: Suhrkamp.

Luther, Martin. 2001. Izbrani spisi. Ur. Nenad Vitorović. Ljubljana: Nova revija.

Marx, Karl, Friedrich Engels in Vladimir Lenin. 1980. O religiji in cerkvi. Izbor in ur. Marko Kerševan. Ljubljana: Komunist.

Od konflikta do skupnosti: Skupno luteransko-katoliško obeleževanje reformacije leta 2017; Poročilo Luteransko-rimskokatoliške komisije za edinost (Cerkveni dokumenti, 150). (2013) 2016. Ljubljana: Družina.

Riesman, David. 1950. The Lonely Crowd: A Study of the Changing American Character. New Haven: Yale University Press.

Schilling, Heinz. 2016. Martin Luther. München: Verlag C. H. Beck.

Simmel, Georg. (1912) 1989. Die gesammelten Schriften zur Religionssoziologie. Berlin: Duncker Humblot.

Sloterdijk, Peter. 1997. „Chancen in Ungeheuren: Notiz zum Gestaltwandel des Religiosen in der modernen Welt." V William James, Die Vielfalt religiöser Erfahrung, 11-34. Frankfurt am Main in Leipzig: Insel Verlag.

Soeffner, Hans Georg. 1992. Die Ordnung der Rituale. Frankfurt am Main: Suhrkamp.

Taylor, Charles. 2001. Wieviel Gemeinschaft braucht die Demokratie? Frankfurt am Main: Suhrkamp.

Troeltsch, Ernst. (1911) 1997. Die Bedeutung des Protestantismus für die Entstehung der modernen Welt. Darmstadt: Wissenschaftliche Verlag

WA (Weimarer Ausgabe). Martin Luther. 1883-2009. Werke. Kritische Gesamtausgabe.

Weber, Max. 1988. Protestantska etika in duh kapitalizma. Ljubljana: Studia humanitatis.

---. 2015. Izbrani spisi iz sociologije religije. Ljubljana: Studia humanitatis.

https://doi.org/10.26493/259o-9754.14(27)11-25 